\title{
Impact of Hello Interval on Performance of AODV Protocol
}

\author{
Nisha Bhanushali \\ Computer Department \\ K.J. Somaiya College of \\ Engineering \\ Mumbai, India
}

\author{
Priyanka Thakkar \\ Computer Department \\ K.J. Somaiya College of \\ Engineering \\ Mumbai, India
}

\author{
Prasanna Shete \\ Computer Department \\ K.J. Somaiya College of \\ Engineering \\ Mumbai, India
}

\begin{abstract}
The multi-hop ad hoc networks are self organizing networks with dynamic topology. The reactive and proactive protocols are designed to handle these dynamically changing networks. Ad Hoc On-Demand Distance Vector (AODV) Routing Protocol is one such Reactive protocol that has been widely adopted in MANETs. In this protocol, routes are maintained as and when required, i.e. they operate 'On Demand'. AODV relies on 'Hello' messages to maintain local link connectivity. The hello messages are sent periodically, the period of which is defined by 'AODV hello interval. In this paper, we investigate the performance of AODV protocol by varying the hello interval. The performance is analyzed in terms of Quality of Service parameters such as throughput, End-to-end Delay and PDR. Our experimental results show that the performance of AODV is improved when hello interval is increased.
\end{abstract}

\section{Categories and Subject Descriptors}

C.2.2 [Network Protocols]: Routing Protocols for ad hoc networks.

\section{General Terms}

Performance, Simulation

\section{Keywords}

MANET, AODV, Hello Interval.

\section{INTRODUCTION}

The multi-hop ad hoc networks have a self-configuring infrastructure with source and destination which are many hops apart from each other. These networks have a dynamically changing topology due to high node mobility, depletion of energy of the node and time varying characteristics of the wireless channel. A large number of routing protocols have been developed so as to overcome these problems. These protocols are distinguished into two types 1) Proactive protocols 2) Reactive Protocols. Proactive protocols are table driven routing protocols where each node maintains routing information for every node in the routing tables and the routing tables are exchanged between the nodes maintaining the network topology. DSDV (Destination Sequenced Distance Vector) [1] and OLSR [2] (Optimized Link-State Routing) are examples of proactive protocols. Reactive protocols maintain the routing information only when it is essential, thus operating "on demand". Few widely used reactive protocols are DSR [3], TORA [4], AODV [5] etc. Ad Hoc On-Demand Distance Vector Routing protocol is one of the most widely used reactive routing protocols. AODV relies on different control packets which are explained in [6]. The different packets are Route Request (RREQ), Route Reply (RREP), Route Error (RERR) and hello messages for routing purpose. 1) In case of route discovery, Route Request messages are broadcasted by a node to all its neighbor nodes to determine route to the destination. 2) Route Reply messages are generated specifically in two situations; one is when the node itself is a destination and second is when the node has an active route to the destination 3) Route Error messages are generated if the node detects a link breakage from the next hop of an active route in its routing table while transmitting the data 4) Hello Messages are used for local link connectivity to determine whether the neighboring nodes are still within the range or alive. This hello messages are sent periodically. The traditional AODV has a default hello interval value of one second. These hello messages thus create an overhead. In case, when there is a continuous communication between the two nodes, the hello messages may cause unnecessary bandwidth usage and hidden energy consumption. The above operational challenges due to hello messages in AODV protocol is explained in [7].

The organization of the remaining paper is as follows, related work done is explained in section 2 , the objective and purpose of this paper is explained in section 3, section 4 describes about the simulation environment in detail, followed by Results and Discussions in section 5 and section 6 provide the Conclusion.

\section{RELATED WORK}

There are various operational challenges faced by the traditional AODV protocol. Hence, optimized routing approaches have been implemented on the traditional AODV protocol. These approaches have been explained in detail in [8]. These approaches help to reduce the problem of unnecessary consumption of node energy and bandwidth by modifying different aspects of the traditional AODV protocol. The discovery of the path to the destination is generally done by flooding during the phase when the route is to be discovered in MANETs wherein the incoming packets are forwarded to the next neighbor node until the destination is reached. This leads to high load on the network due to broadcast storm problem and hence, leads to unnecessary consumption of the node energy. To overcome this problem Hybrid Flooding Scheme [9] was used. When the broken links are generated control messages needs to be reduced which is one of the main objectives of this scheme. This scheme also differentiates between the forwarding nodes. The Gossip and signal strength based routing are combined in the RSS Gossip AODV [10] approach. Here, flooding of the RREQ is controlled by controlling the gossip probability based on RSS of the received network. This is done to overcome the 
problem of unnecessary consumption of the node energy faced when the RREQ is received along the weak links. Approaches like Cross Layer Weighted Position-Based Routing Protocol (CLWPR) [11] rely on these 1-hop Hello Messages that are periodically broadcasted. This messages store position information like location co-ordinates, velocity etc. to improve the efficiency of the network by decreasing the end-to-end delay.

\section{OBJECTIVE AND PURPOSE}

In order to maintain the established routes, AODV uses periodic beckoning of hello messages. The hello messages do not play a significant role in case there is a continuous communication taking place between the two nodes rather they result in unnecessary consumption of channel bandwidth and node energy.

The objective of this paper is to study the effect of periodic hello messages on the performance of AODV protocol. In order to analyze the effect of hello messages, we propose to run the AODV protocol with different hello intervals and see the effect of it on the network performance.

\section{SIMULATION ENVIRONMENT}

The hello messages are required mainly when the communication between the neighboring nodes is lost or the communication is reduced. The hello messages do not have a significant role in case there is a continuous communication taking place between the two nodes and hence, there is an unusual consumption of the bandwidth and energy. In order to study the effect of hello messages on the performance of AODV protocol, we carry out simulations using a simulator called QualNet, which provides a comprehensive environment for designing protocols, creating and animating network scenarios and analyzing their performance.

We carried out the simulations of the traditional AODV protocol by setting the hello interval to the default value of 1 second and analyzed the performance in both environmentsRandom and Grid. This hello interval was then changed to 2 seconds and 3 second and the performance changes were noted. Finally we disabled the broadcasting of hello messages and analyzed the performance of the network where no hello messages were sent for local link connectivity. The parameter settings for each simulation are explained in detail in the next section.

\section{RESULTS AND DISCUSSION}

The QualNet 5.0 network simulator is used for the analysis of traditional AODV protocol over IEEE 802.11 MAC/PHY layer protocol which is mentioned in [12].

For this, we have made use of two types of environments:-

1) Node Placement- Grid with no mobility

In this scenario, the nodes are placed in a grid format with a fixed size of $\left(\mathrm{N}^{*} \mathrm{~N}\right)$ area where the value of $\mathrm{N}$ ranges from 3 to 10 . We have set the data rate to $32 \mathrm{Kbps}$. In a network of mobile devices where the number of devices range from 9 to 100 were placed in a grid forming a regular lattice graph of degree 4 and a single CBR traffic flow was set between diagonally opposite nodes. We observed the performance of AODV protocol for dense as well as sparse networks. For each network hello
Table 1. Simulation Parameters

\begin{tabular}{|l|l|}
\hline Parameter & Value \\
\hline No. of Nodes and Area & $\begin{array}{l}9,16,25,36,49,64,81,100 \text { and } \\
1500 \mathrm{~m} * 1500 \mathrm{~m}\end{array}$ \\
\hline $\begin{array}{l}\text { Node Placement } \\
\text { Strategy }\end{array}$ & Grid [Grid unit $=250 \mathrm{~m}]$ \\
\hline Simulation Time & 3 minutes \\
\hline Channel Frequency & $2.4 \mathrm{GHz}$ \\
\hline Path Loss Model & Two ray Model \\
\hline Transmission Range & $350 \mathrm{~m}$ \\
\hline $\begin{array}{l}\text { PHY / MAC Layer } \\
\text { Protocol }\end{array}$ & IEEE $802.11 \mathrm{~b}$ \\
\hline Traffic Sending Rate & $32 \mathrm{kbps}$ \\
\hline Payload size & 512 bytes \\
\hline
\end{tabular}

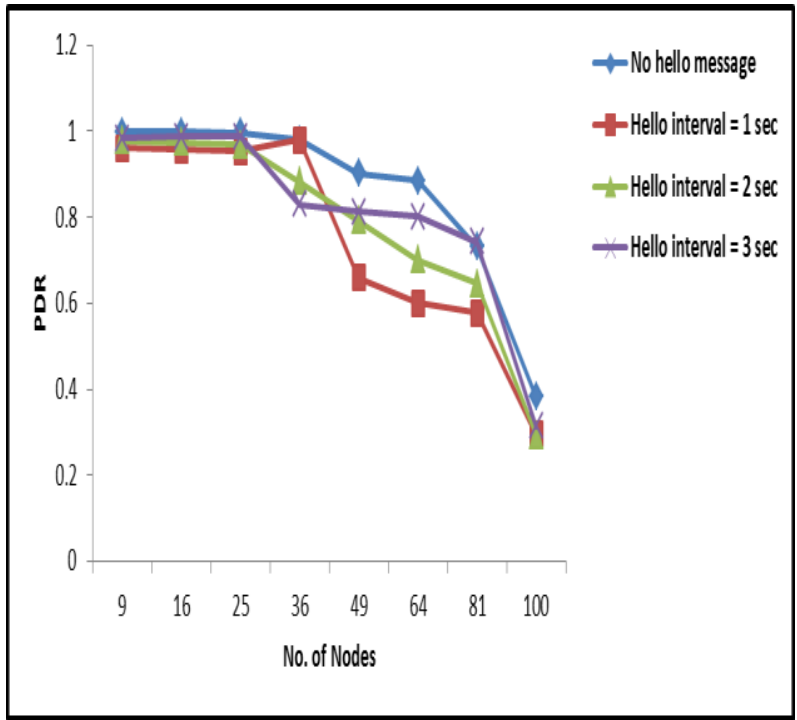

Figure 1: Packet Delivery Ratio vs. No. of nodes

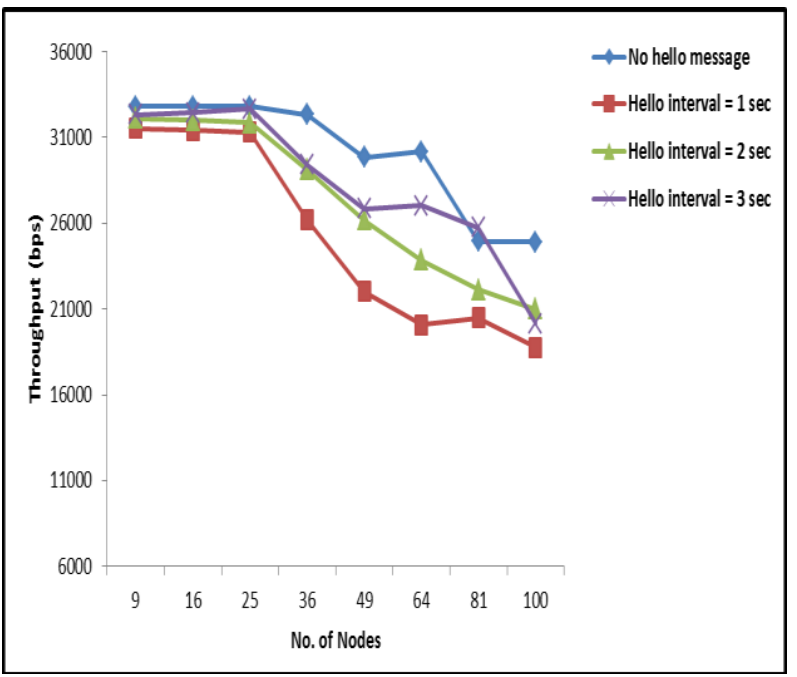

Figure 2 Throughput vs. Number of nodes 


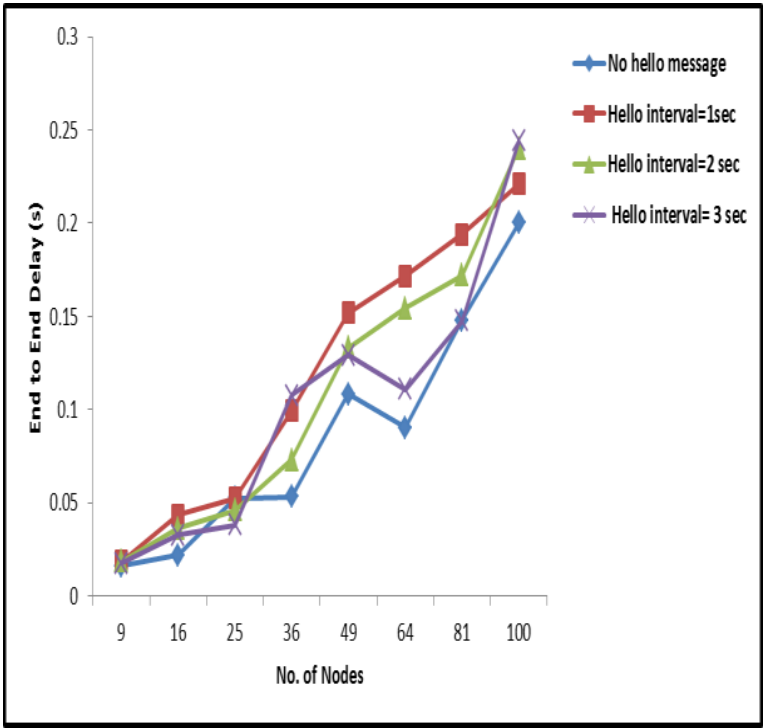

Figure 3 End to End delay vs. Number of nodes

The above simulation results show that the network with no mobility has a maximum end-to-end delay when the hello interval is set to 1 and is least when no hello messages have been sent. The throughput is maximized for no hello message and is least when hello interval is 1 and the packet delivery ratio for no hello messages is maximized while for hello interval 1 is minimized.

\section{1) Node Placement- Random with Random Waypoint} mobility of $5 \mathrm{~m} / \mathrm{s}$

In this simulation, the mobile devices are placed in random format and the data rate is set to $32 \mathrm{Kbps}$ having a single CBR data flow. The parameter setting for random environment with node mobility set to $5 \mathrm{~m} / \mathrm{s}$ is given in the Table 2.1 .

Table 2.1 Simulation Parameters

\begin{tabular}{|l|l|}
\hline Parameter & Value \\
\hline No. of Nodes and Area & $\begin{array}{l}10,20,30,40,50 \text { and } \\
1500 \mathrm{~m} * 1500 \mathrm{~m}\end{array}$ \\
\hline $\begin{array}{l}\text { Node Placement } \\
\text { Strategy }\end{array}$ & Random waypoint \\
\hline Simulation Time & 3 minutes \\
\hline Channel Frequency & $2.4 \mathrm{GHz}$ \\
\hline Path Loss Model & Two ray Model \\
\hline Transmission Range & $350 \mathrm{~m}$ \\
\hline $\begin{array}{l}\text { PHY / MAC Layer } \\
\text { Protocol }\end{array}$ & IEEE $802.11 \mathrm{~b}$ \\
\hline Traffic Sending Rate & $32 \mathrm{kbps}$ \\
\hline
\end{tabular}

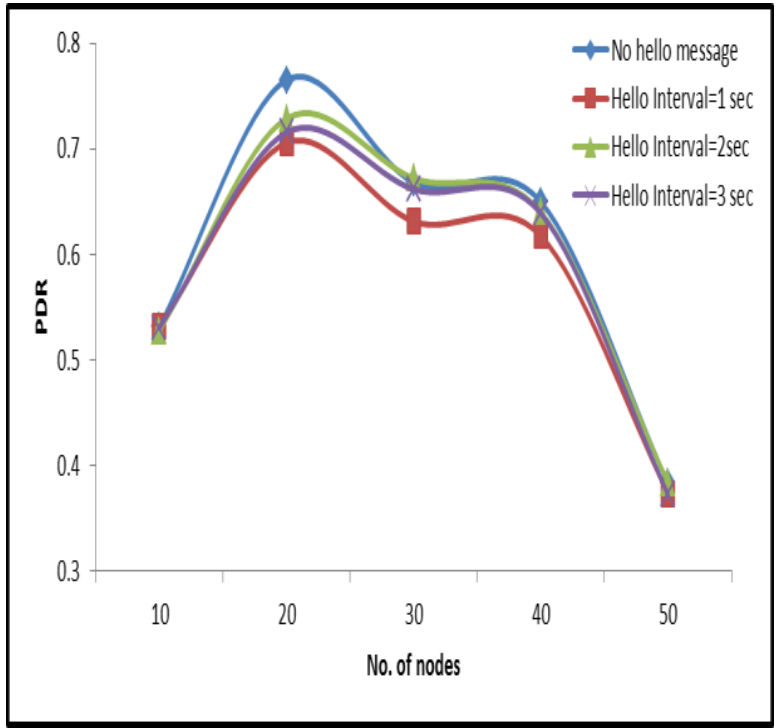

Figure 2.1.1 Packet Delivery Ratio vs. Number of nodes

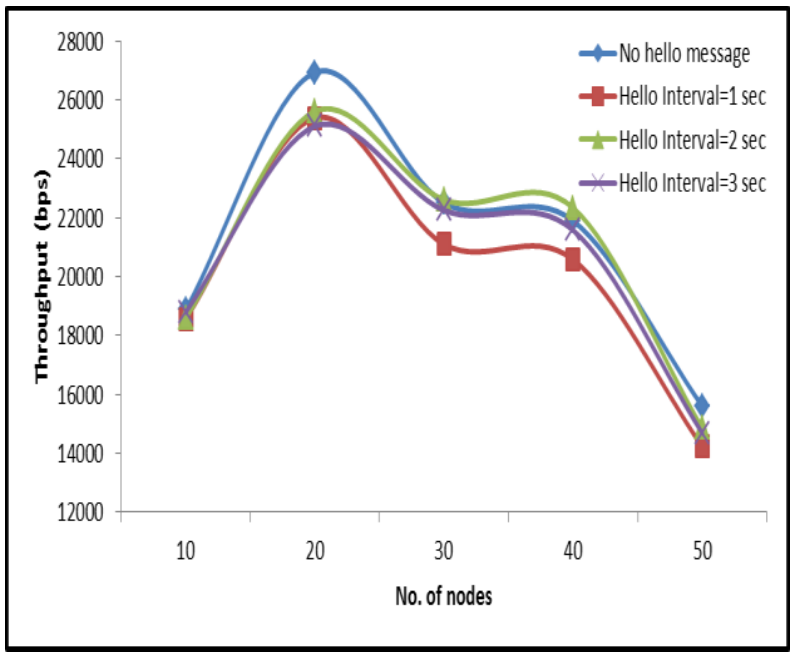

Figure 2.1.2 Throughput vs Number of nodes

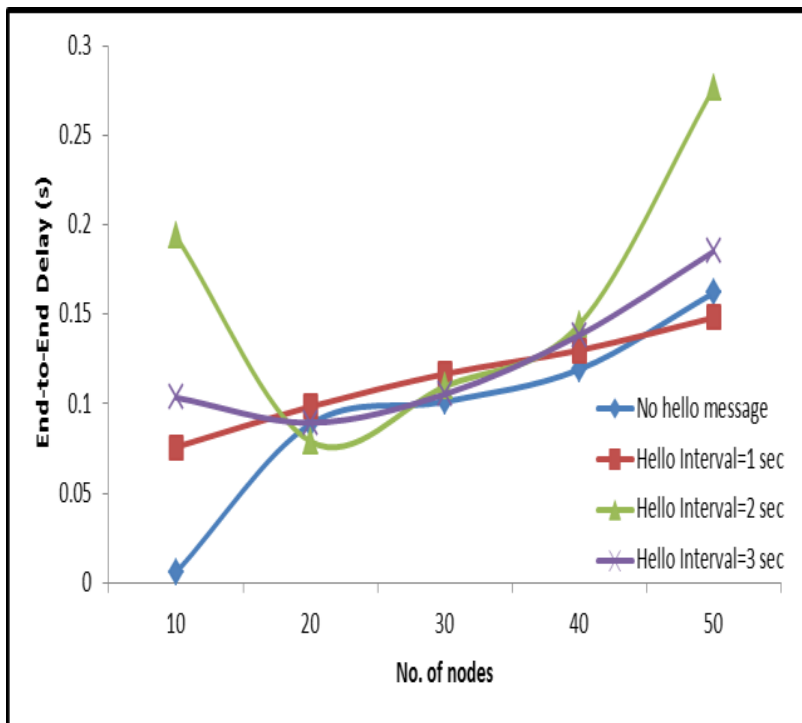

Figure 2.1.3 . End to End Delay vs Number of nodes 
The above simulation results show that the network with random node placement and node mobility set to $5 \mathrm{~m} / \mathrm{s}$ has maximum end-to-end delay when hello interval is set to 1 and is least when no hello messages have been sent. The throughput is maximized for no hello message and is least for hello interval 1 and the packet delivery ratio for no hello message is maximized while for hello interval 1 is minimized.

\section{2) Node Placement- Random with Random Waypoint} mobility of $10 \mathrm{~m} / \mathrm{s}$

In this simulation, the mobile devices are placed in random format and the data rate is set to $32 \mathrm{Kbps}$ having a single CBR data flow. The parameter setting for random environment with node mobility set to $10 \mathrm{~m} / \mathrm{s}$ is given in the Table 2.2

Table 2.2 Simulation Parameters

\begin{tabular}{|l|l|}
\hline Parameter & Value \\
\hline No. of Nodes and Area & $\begin{array}{l}10,20,30,40,50 \text { and } \\
1500 \mathrm{~m} * 1500 \mathrm{~m}\end{array}$ \\
\hline $\begin{array}{l}\text { Node Placement } \\
\text { Strategy }\end{array}$ & Random waypoint \\
\hline Simulation Time & 3 minutes \\
\hline Channel Frequency & $2.4 \mathrm{GHz}$ \\
\hline Path Loss Model & Two ray Model \\
\hline Transmission Range & $350 \mathrm{~m}$ \\
\hline $\begin{array}{l}\text { PHY / MAC Layer } \\
\text { Protocol }\end{array}$ & IEEE $802.11 \mathrm{~b}$ \\
\hline Traffic Sending Rate & $32 \mathrm{kbps}$ \\
\hline
\end{tabular}

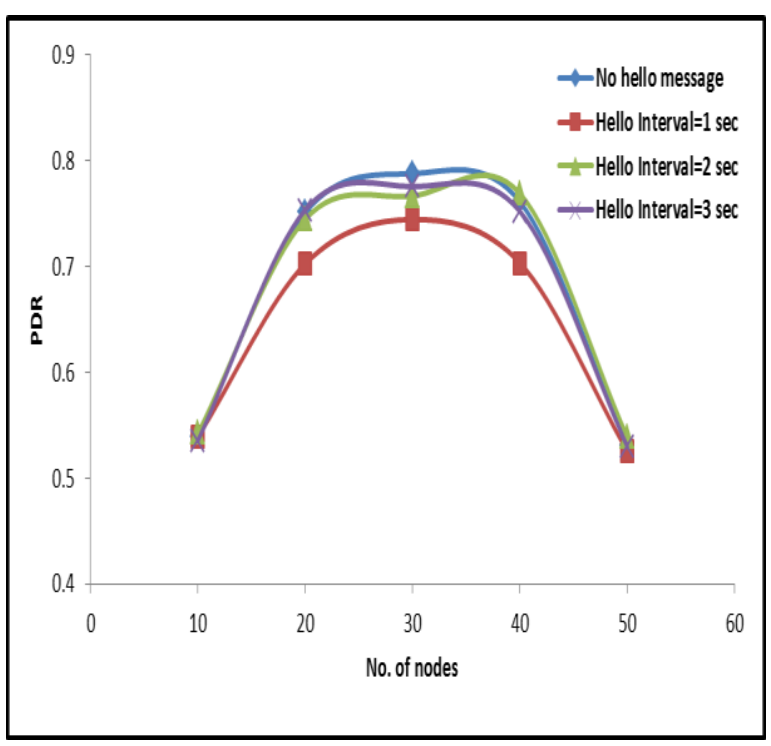

Figure 2.2.1 Packet Delivery Ratio vs. Number of nodes

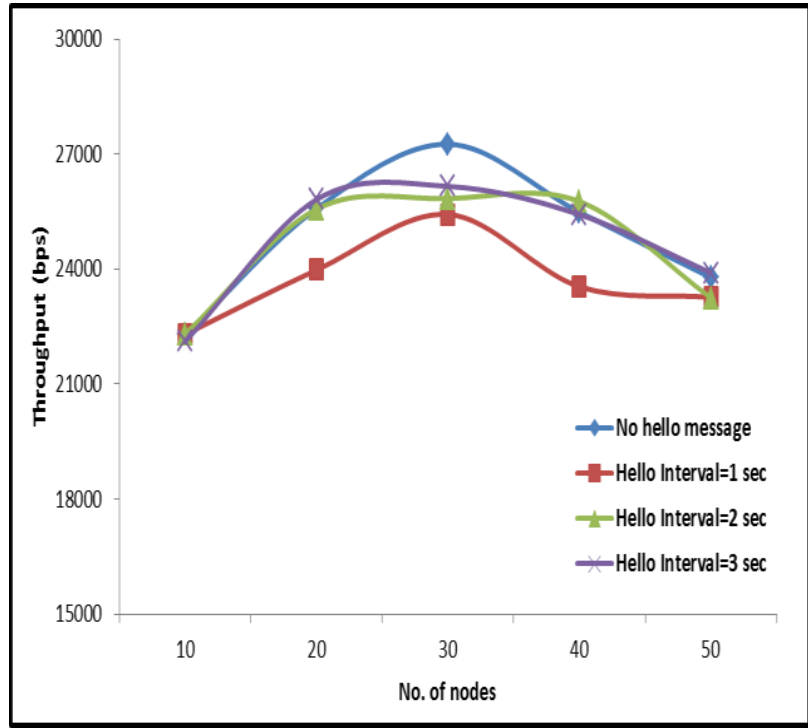

Figure 2.2.2 Throughput vs Number of nodes

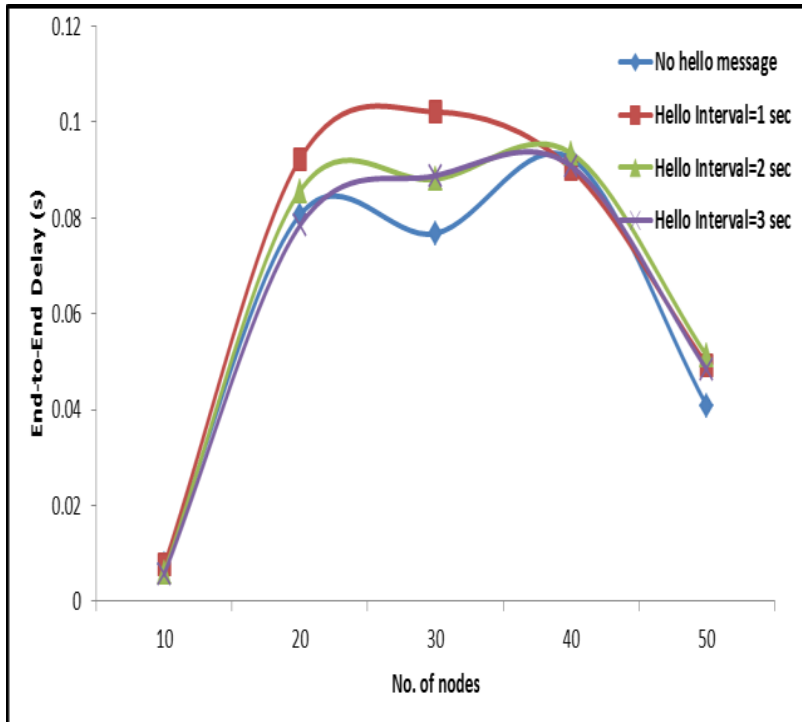

Figure 2.2.3 End to End Delay vs Number of nodes

The above simulation results show that the network with random node placement and node mobility set to $10 \mathrm{~m} / \mathrm{s}$ has maximum end-to-end delay when hello interval is set to 1 and is least when no hello messages have been sent. The throughput is maximized for no hello message and is least for hello interval 1 and the packet delivery ratio for no hello message is maximized while for hello interval 1 is minimized.

\section{CONCLUSION}

In this paper, we have analyzed on the effect of 'hello interval' on the network performance of AODV protocol. Our simulation results show that in all scenarios i.e. grid topology without mobility, nodes moving at $5 \mathrm{~m} / \mathrm{s}$ and $10 \mathrm{~m} / \mathrm{s}$, the AODV performance is better when hello interval is large. In all scenarios considered above, the performance is worst for hello interval of $1 \mathrm{sec}$ and the best performance of the network is when no hello messages have been broadcast. In future, we would be suppressing the unnecessary hello messages by making the hello interval adaptive and proportional to the event interval which will reduce the consumption of the node energy and bandwidth. The rest of the routing behavior will be same as the conventional AODV protocol. 


\section{ACKNOWLEDGMENT}

Through this acknowledgement, we express our sincere gratitude to all those people who have been associated with this project and helped us with it and made it a worthwhile experience. We are also grateful to our institution and our faculty members for the provision of expertise and technical support in the implementation.

\section{REFERENCES}

[1] C. E. Perkins, P. Bhagwat, "Highly Dynamic Destination-Sequenced Distance Vector Routing Protocol (DSDV) for Mobile Computers", Proceedings of ACM SIGCOMM 1994, pp. 234-244, Aug 1994.

[2] T. Clausen, P. Jacquet, A. Laouiti, P. Muhlethaler, A. Qayyum, and L. Viennot. "Optimized Link State Routing Protocol," in Proceedings of IEEE INMIC, Dec. 2001.

[3] D. B. Johnson, D. A. Maltz, "Dynamic Source Routing in Ad Hoc Wireless Networks", Mobile Computing, Kluwer Academic Publishers, vol. 353, pp. 153-181, 1996.

[4] V. D. Park and M. S. Corson, "A Highly Adaptive Distributed Routing Algorithm for Mobile Wireless Networks", Proceedings of IEEE INFOCOM 1997, pp. 1405-1413, April 1997.

[5] C. E. Perkins, E. M. Royer, "Ad Hoc On-Demand Distance Vector Routing", Proceedings of IEEE Workshop on Mobile Computing Systems and Applications, pp. 90-100, February 1999.
[6] C. Perkins and S.das "Ad Hoc On Demand Distance Vector Routing (AODV) Routing Request For Comments (RFC) July 2003.

[7] S. Y. Han and D. Lee, "An Adaptive Hello Messaging Scheme for Neighbor Discovery in On-Demand MANET Routing Protocols", IEEE COMMUNICATIONS LETTERS, VOL. 117, N0. 5,pp. 1040-1043,MAY 2013.

[8] P. J. Shete, R. N. Awale, "Routing Protocols for Multihop Ad Hoc Networks: Operational Challenges and Design Optimizations", International Journal of Computer Applications, Vol. 84, No. 6, Dec 2013.

[9] D. G. Reina, S. L. Toral, P. Jonhson, and F. Barrero, "Hybrid Flooding Scheme for Mobile Ad Hoc Networks", IEEE COMMUNICATIONS LETTERS, VOL.17, NO. 3, pp. 592-595, MARCH 2013.

[10] P. J. Shete, R. N. Awale, "RSS-Gossip AODV: Received Signal Strength based Gossip Flooding Mechanism for AODV", October 2014.

[11] K. Katsaros, M. Dianati, R. Tafazolli and R. Kernchen, "CLWPR - A Novel Cross-Layer Optimized Position Based Routing Protocol for VANETs", Proceedings of IEEE Vehicular Networking Conference (VNC), pp. 139-146, Nov. 2011.

[12] User Manual QualNet Network Simulator, Version 5.0.2 